\title{
OPEN Magnetic core-modified silver nanoparticles for ibuprofen removal: an emerging pollutant in waters
}

\begin{abstract}
Yesica Vicente-Martínez ${ }^{\bowtie}$, Manuel Caravaca, Antonio Soto-Meca \& Rubén Solana-González
In this work we present a novel procedure for ibuprofen adsorption from waters employing magnetic core-modified silver nanoparticles. We demonstrate that $93 \%$ adsorption of ibuprofen is achieved in $45 \mathrm{~min}$ by means of a simple method, for neutral $\mathrm{pH}$ and room temperature, also using a low dose of adsorbent, equal to $7 \mathrm{mg}$ in $500 \mu \mathrm{L}$ of suspension. The characterization of the adsorbent, before and after adsorption, was carried out by means of field emission scanning electron microscopy, energy dispersive X-ray spectroscopy, BET analysis, Fourier-transform infrared spectroscopy and differential scanning calorimetry. It is worth pointing out that ibuprofen can be desorbed and the adsorbent can be reused, remaining unaltered for the first three cycles, and showing $89.3 \%$ adsorption efficiency after the third regeneration. A three-parameter model and the Langmuir isotherm characterize the kinetics and isotherm of adsorption.
\end{abstract}

Pharmaceuticals are products used in large doses in daily life considered as contaminants of emerging concern. Due to the large amounts of drugs consumed, the hydrogenic sources suffer from contamination processes that give rise to toxicological effects in humans despite its low concentrations $s^{1,2}$. Many medicines considered as emerging contaminants are constantly detected in groundwater, wastewater treatment plants and water supply. The inefficiency of conventional methods used in water treatment plants to remove the contaminant motivates the development of effective methods to treat effluent contamination ${ }^{3}$.

According to the physico-chemical properties of drugs, their degradation products and the characteristics of the soils, these substances can reach the groundwater and contaminate the aquifers or remain retained in the soil, thus affecting the ecosystem and humans through the food chain ${ }^{4}$. Additionally, the portion of medicines not assimilated by the organism, as well as chemical substances administered to animals, usually become part of wastewater. Consequently, different ways of removing medicines in waters have been studied ${ }^{5}$.

Recently, Ibuprofen (IB), a medicine from the family of non-steroidal anti-inflammatories, used against muscle problems and inflammatory disorders, has become an important research focus, since it is an emerging micro-pollutant with a high economic and environmental impact ${ }^{6}$. It is widely used in society, presenting a chemical structure not easily degradable, being eliminated from the body through urine. Due to this, it can be found in water samples of different origins, thus even affecting the swimming capacity of aquatic species and, therefore, its ability to move, feed and reproduce ${ }^{7,8}$.

Some of the methods to eliminate IB from water samples are based on its degradation or oxidation. In the former case, it is worth pointing out the employment of microorganisms through biodegradation ${ }^{9}$, biotransformation ${ }^{10}$, photocatalytic process with $\mathrm{TiO}_{2}{ }^{11}$ and coagulants methods ${ }^{12}$. In the latter case, IB is oxidized by using sulfates thermally assisted by ultraviolet light ${ }^{13}$. Other relevant methods include the use of peroxymonosulfate activation under visible-light irradiation ${ }^{14}$, graphene oxide based heterogenous catalytic ozonation ${ }^{15}$, strong nano-clay composite ${ }^{16}$ or electro-fenton process ${ }^{17}$.

Notwithstanding, the methods based on adsorption have been the most used in recent years to remove IB from aqueous media due to its high removal efficiency, being the adsorbents of very diverse nature. Ibuprofen has been adsorbed on Organo-Zeolite ${ }^{18}$, activated carbon cloths ${ }^{19}$, mesoporous silicon microparticles ${ }^{20}$, activated carbon ${ }^{21-23}$ or mica and montmorillonite ${ }^{24}$, polymeric resins ${ }^{25}$, functionalized materials ${ }^{26}$, waste-based adsorbents ${ }^{27}$, or biosorbents $s^{28}$, among others. Some current methods employed to remove ibuprofen from aqueous samples are very laborious and require long times to reach the results ${ }^{29,30}$, other procedures demand large 
amounts of adsorbent ${ }^{31}$ or high temperatures. However, in the present method high adsorption efficiency is achieved under mild experimental conditions such as neutral $\mathrm{pH}$ and room temperature. Furthermore, it takes only a few minutes to achieve the complete removal of ibuprofen.

In particular, nanoparticles have been employed in recent studies to remove different pollutants ${ }^{32,33}$ from water. Particularly, these have been employed to remove IB from different media due to its very small size and high contact surface, thus achieving high adsorption efficiency ${ }^{34-36}$. In this work, magnetic core-modified silver nanoparticles ( $\mathrm{Fe}_{3} \mathrm{O}_{4} @ \mathrm{AgNPs}$ ) have been used to adsorb ibuprofen from aqueous solutions, being a new outstanding method for reaching high removal efficiency, under very mild conditions and in a short time compared with other procedures ${ }^{21,37,38}$. $\mathrm{Fe}_{3} \mathrm{O}_{4} @ \mathrm{AgNPs}$ are easily synthetized and removed from media using a magnet. Additionally, IB can be desorbed from the nanoparticles for them to be reused.

\section{Experimental}

Materials and instrumentation. Pure water obtained with a Millipore system (Millipore, Bedford, MA, USA) was used exclusively. All the solutions were stored in polypropylene or polytetrafluoroethylene vessels. Analytical grade acetonitrile was obtained from Panreac. The standard IB and the other chemicals used were purchased from Sigma-Aldrich.

The concentrations of IB were determined by HPLC (high performance liquid chromatography) on a JASCO BS-4000 system equipped with a sample injector and an ultraviolet detector at $254 \mathrm{~nm}$. A C18 column (150 $\times 4.6 \mathrm{~mm}$ i.d., $5 \mu \mathrm{m}$ ) was used. It was employed as a mobile phase $80 \%$ acetonitrile and $20 \%$ phosphoric acid solution at $\mathrm{pH}$ 3. The flow rate was $1 \mathrm{~mL} \mathrm{~min}^{-1}$ and the injection volume was $10 \mu \mathrm{L}$. The reproducibility and repeatability of the HPLC method were checked by means of an IB standard solution.

Permanent Nd-Fe-B magnets were supplied by Supermagnete (Gottmadingen, Germany). The agitator used to manufacture the nanoparticles was a polyethylene shovel agitator purchased from Argolab (AM20-D model).

Preparation of magnetic core-modified silver nanoparticles ( $\left.\mathrm{Fe}_{3} \mathrm{O}_{4} @ \mathrm{AgNPs}\right) .20 \mathrm{~mL}$ of water was heated at $80{ }^{\circ} \mathrm{C}$ and continuously stirred under nitrogen atmosphere. Then, $0.56 \mathrm{~g} \mathrm{FeCl}_{3} \cdot 6 \mathrm{H}_{2} \mathrm{O}$ and $0.2 \mathrm{~g}$ $\mathrm{FeCl}_{2} \cdot 4 \mathrm{H}_{2} \mathrm{O}$ were added. When the solids were dissolved, $2 \mathrm{~mL}$ of concentrated ammonia solution were incorporated and the solution was stirred for $10 \mathrm{~min}$. The particles were separated using a permanent magnet and the supernatant was discarded. The solid was washed three times with water until the washing liquids were neutral. The iron oxide nanoparticles obtained in this way (approximately $0.28 \mathrm{~g} \mathrm{Fe}_{3} \mathrm{O}_{4}$ ) were suspended in $20 \mathrm{~mL}$ of water. Then, $5.7 \mathrm{~mL}$ of diluted silver nitrate solution $\left(0.011 \mathrm{~g} \mathrm{~L}^{-1}\right)$ were added, the mixture was stirred for $5 \mathrm{~min}$ and using the magnet were separated and washed several time with water. Finally, these particles $\left(\mathrm{Fe}_{3} \mathrm{O}_{4} @\right.$ AgNPs) were suspended in $20 \mathrm{ml}$ of water again ${ }^{39}$.

A Field emission scanning electron microscopy analysis (FESEM) was performed to check the presence of Ag in the samples. In Fig. 1 (top) it is shown the $3 \mathrm{D}$ image for $\mathrm{Fe}_{3} \mathrm{O}_{4}$, while Fig. 1 (bottom) shows the intensity image for $\mathrm{Fe}_{3} \mathrm{O}_{4} @ \mathrm{AgNPs}$, where the Ag appears as spherical, and shiny due to its high atomic number. Additionally, energy dispersive X-ray spectroscopy (EDX) graphs for $\mathrm{Fe}_{3} \mathrm{O}_{4}$ and $\mathrm{Fe}_{3} \mathrm{O}_{4} @ A g N P$ are presented in Fig. 2, top and bottom, respectively. In the latter, the signal corresponding to Ag appears in the plot.

A BET test was carried out to determine the contact surface area of the adsorbent, giving a value equal to $116.476 \mathrm{~m}^{2} / \mathrm{g}$, and a correlation coefficient for the BET isotherm of 0.999 .

\section{Results and discussion}

Ibuprofen adsorption procedure.. A water sample $(10 \mathrm{~mL})$ containing IB at a concentration of $0.2 \mathrm{mg}$ $\mathrm{L}^{-1}$ was placed in a polypropylene tube, $500 \mu \mathrm{L}$ of $\mathrm{Fe}_{3} \mathrm{O}_{4} @ \mathrm{AgNPs}$ suspension were added. After shaking 30 min at $T=298 \mathrm{~K}$, the magnet was placed at the bottom of the tube for $5 \mathrm{~min}$ and the adsorbent was separated. The supernatant was analyzed by high performance liquid chromatography to determine the maximum removal efficiency of IB.

Several studies have been performed to check the presence of IB in $\mathrm{Fe}_{3} \mathrm{O}_{4} @ \mathrm{AgNPs}$ samples after adsorption. Fig. S1 (see Supplementary Material) shows a Fourier-transform infrared spectroscopy (FTIR) spectrum for $\mathrm{Fe}_{3} \mathrm{O}_{4} @ \mathrm{AgNPs}$ after the adsorption process, where the characteristic IB signals are marked (carbonyl group at $1704,12 \mathrm{~cm}^{-1}$; stretch frequencies of $\mathrm{Csp}^{3}-\mathrm{H}$ of isobutyl group at 2951,93 and $2922,15 \mathrm{~cm}^{-1}$; aromatic $\mathrm{C}=\mathrm{C}$ bond at $1560,83 \mathrm{~cm}^{-1}$; O-H bond at $3100 \mathrm{~cm}^{-1}$ ). In Fig. S2 (top) (see Supplementary Material), a differential scanning calorimetry (DSC) analysis for pure IB is shown, while in Fig. S2 (bottom) (see Supplementary Material) the same study is presented for IB adsorbed onto $\mathrm{Fe}_{3} \mathrm{O}_{4} @ A g N P s$. In the latter, the double peak presented in the striped area reveals the strong interaction between the species.

Regarding the effect of temperature on the adsorption process, it was found that for $T=298$ and $303 \mathrm{~K}$, the adsorption efficiency reaches the same value, maximum. For $T$ greater than $303 \mathrm{~K}, \mathrm{Fe}_{3} \mathrm{O}_{4} @ \mathrm{AgNPs}$ is dissolved in the media. The choice for the adsorption procedure was then $298 \mathrm{~K}$. However, in "Adsorption isotherms" we perform a thermodynamic study for temperatures above $303 \mathrm{~K}$, once the $\mathrm{Fe}_{3} \mathrm{O}_{4} @ \mathrm{AgNPs}$ is dissolved, in order to complete the characterization adsorption process of the involved species.

Effect of $\mathrm{pH}$ on IB adsorption. The effect of $\mathrm{pH}$ on the adsorption of IB on magnetic core-modified silver nanoparticles was studied within the range 1-10. Figure 3 shows that the highest degree of adsorption was achieved at $\mathrm{pH}$ 7. The dependence of adsorption on $\mathrm{pH}$ is associated with the point of zero charge (PZC) of the adsorbent $\left(\mathrm{Fe}_{3} \mathrm{O}_{4} @ \mathrm{AgNPs}\right)$ and the pKa of the IB. The PZC is 6.93 for $\mathrm{Ag}^{40}$. The IB is a weak acid $(\mathrm{pKa}=5.2)$ and exists as a neutral species por $\mathrm{pH}<\mathrm{pKa}$, coexists as neutral and anionic species at $\mathrm{pH} \cong \mathrm{pKa}$, and exists as anion species for $\mathrm{pH}>\mathrm{pKa}^{41}$. For $\mathrm{pH}>8 \mathrm{IB}$ is deprotonated and $\mathrm{Ag}$ surface becomes negatively charged, thus leading to an electrostatic repulsion which reduces the adsorption efficiency ${ }^{37}$. For $\mathrm{pH}$ values greater than $\mathrm{pKa}$ but lower 


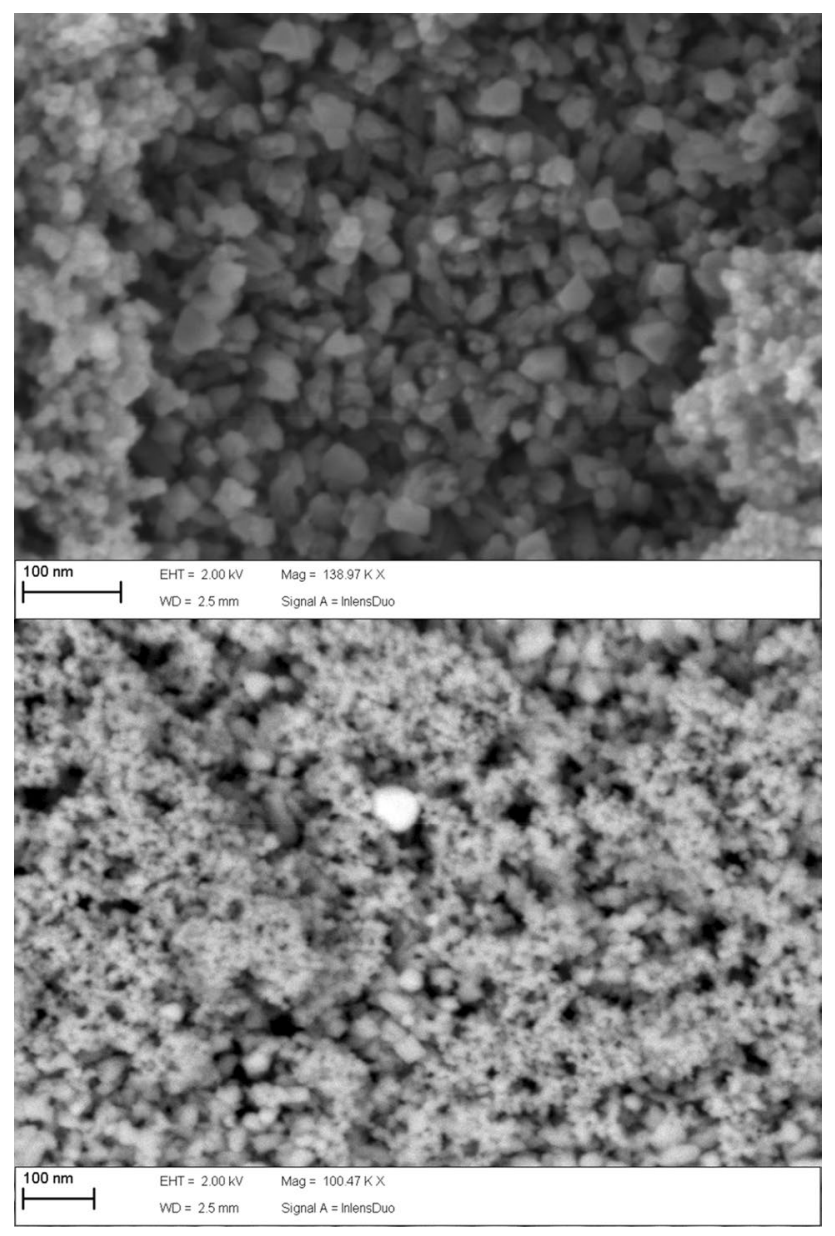

Figure 1. FESEM images for $\mathrm{Fe}_{3} \mathrm{O}_{4}\left(3 \mathrm{D}\right.$, top) and $\mathrm{Fe}_{3} \mathrm{O}_{4} @ \mathrm{AgNPs}$ (intensity, bottom). The latter reveals the presence of $\mathrm{Ag}$ in the sample.

than PZC, electrostatic attraction between anionic ibuprofen and the positively charged surface of silver nanoparticle improves the adsorption capacity ${ }^{42}$. For $\mathrm{pH}<\mathrm{pKa} \mathrm{IB}$ is mainly in its protonated form (non-ionized) and Ag surface is positively charged, being adsorption mainly conducted by Van der Waals or hydrogen bonding interactions ${ }^{43}$.

An increase in the ionic strength of the solution reduces the electrostatic interactions, either attractive or repulsive, due to a screening effect of the surface charge produced by the reduction of $\mathrm{pH}^{44}$. This presumably explains the reason why increased ionic strength resulted in the decreased sorption of ibuprofen in the low $\mathrm{pH}$ range ${ }^{45}$. The ionic strength could affect the activity coefficients hindering the transfer from the solution to the adsorptive surface ${ }^{46}$.

Effect of adsorbent volume. The volume of $\mathrm{Fe}_{3} \mathrm{O}_{4} @ \mathrm{AgNPs}$ suspension has been studied from 100 to 1000 $\mu \mathrm{L}$ for IB concentration of $0.02 \mathrm{mg} \mathrm{L}^{-1}$. The results are shown in Fig. 4 . As it is depicted, the volume necessary of $\mathrm{Fe}_{3} \mathrm{O}_{4} @ \mathrm{AgNPs}$ to reach the maximum adsorption efficiency is $500 \mu \mathrm{L}$. From $900 \mu \mathrm{L}$, the percentage of adsorption decreases due to the high volume of adsorbent in the medium and it is not completely removed with the magnet.

Contact time effect. The contact time between $\mathrm{Fe}_{3} \mathrm{O}_{4} @$ AgNPs and the solution containing IB was studied from 1 to $90 \mathrm{~min}$ in order to achieve the maximum adsorption efficiency, reached at $45 \mathrm{~min}$. From there, the percentage of adsorption remains constant until $90 \mathrm{~min}$, as shown in Fig. 5. The solid line represents the fit to the efficient hybrid combined first and second order three-parameter model ${ }^{47}$ :

$$
\text { Adsorption efficiency }(A E)=(\alpha-\beta) \frac{(\beta / \alpha) e^{(\beta-\alpha) \gamma t}}{(\beta / \alpha) e^{(\beta-\alpha) \gamma t}-1}+\beta
$$

where $\alpha, \beta, \gamma$ are characteristic paremeters. The fit was carried out via software Origin 2019 , offering $R^{2}=0.99986$ and recuded $\chi^{2}=0.39$. Although this model is credited to be consistent with equilibrium parameters, pseudofirst and pseudo-second order kinetic models were also conducted ${ }^{48}$ : 

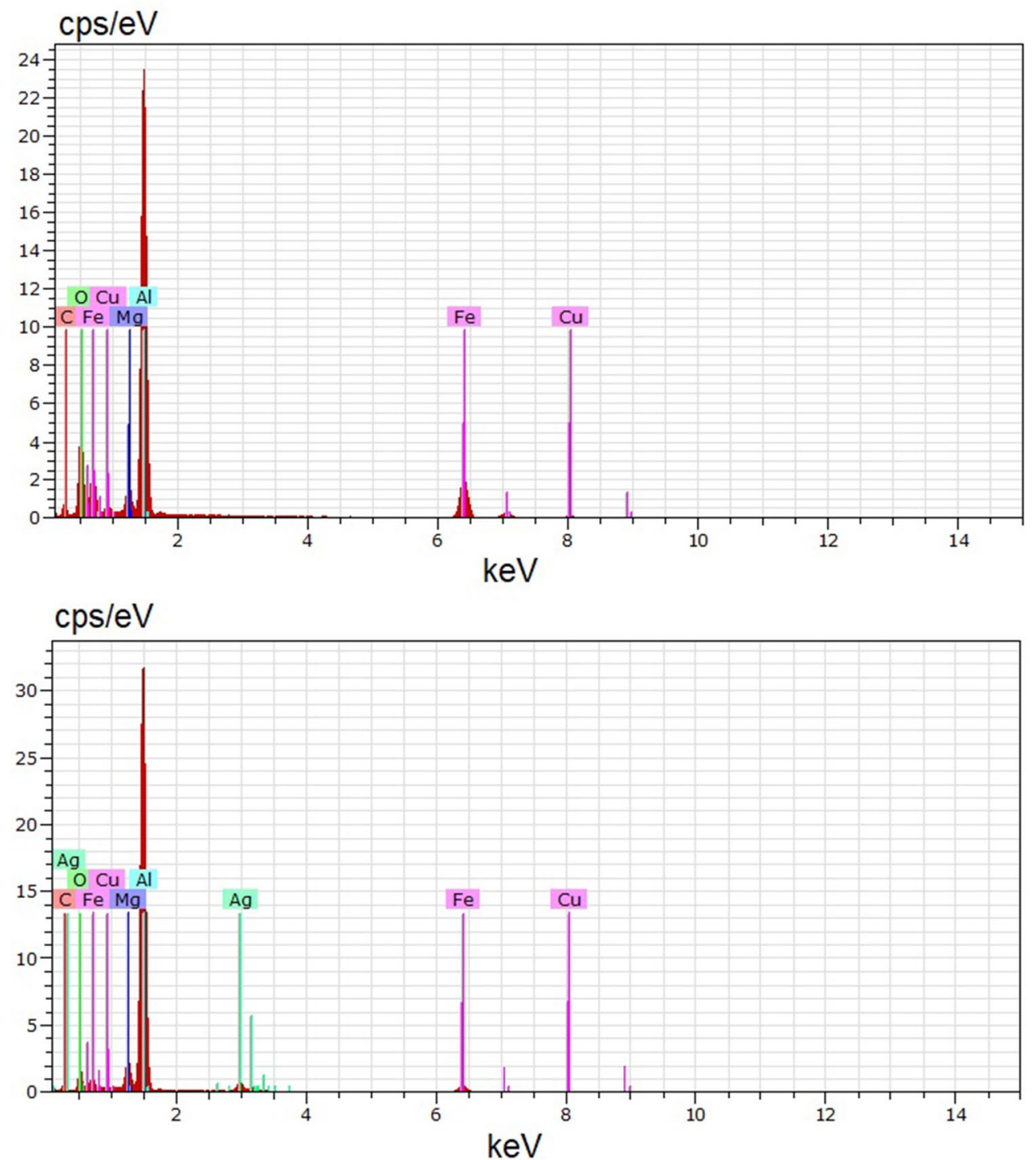

Figure 2. EDX graphs for $\mathrm{Fe}_{3} \mathrm{O}_{4}$ (top) and $\mathrm{Fe}_{3} \mathrm{O}_{4} @ \mathrm{AgNPs}$ (bottom) obtained from the FESEM analysis of Fig. 1. In the latter, peaks corresponding to Ag appear in the plot, checking the presence of Ag in the sample.

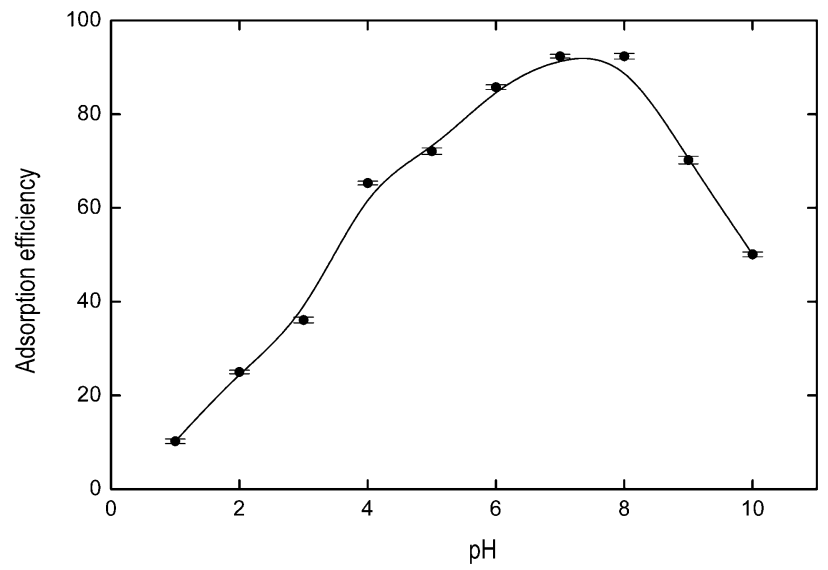

Figure 3. Effect of $\mathrm{pH}$ on the ibuprofen adsorption. 


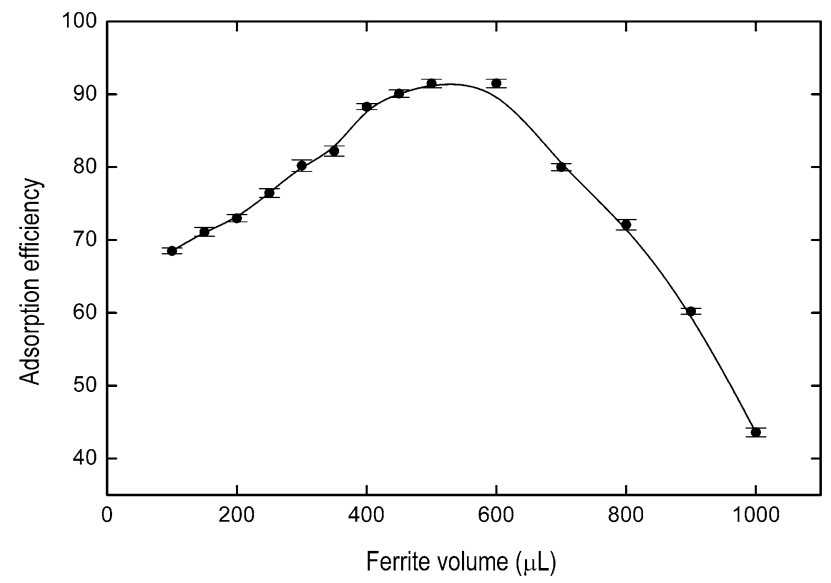

Figure 4. Dependence of the adsorption efficiency on $\mathrm{Fe}_{3} \mathrm{O}_{4} @ \mathrm{AgNPs}$ suspension volume for an ibuprofen concentration equal to $0.02 \mathrm{mg} \mathrm{L}^{-1}$. Solid line represents B-spline connectors.

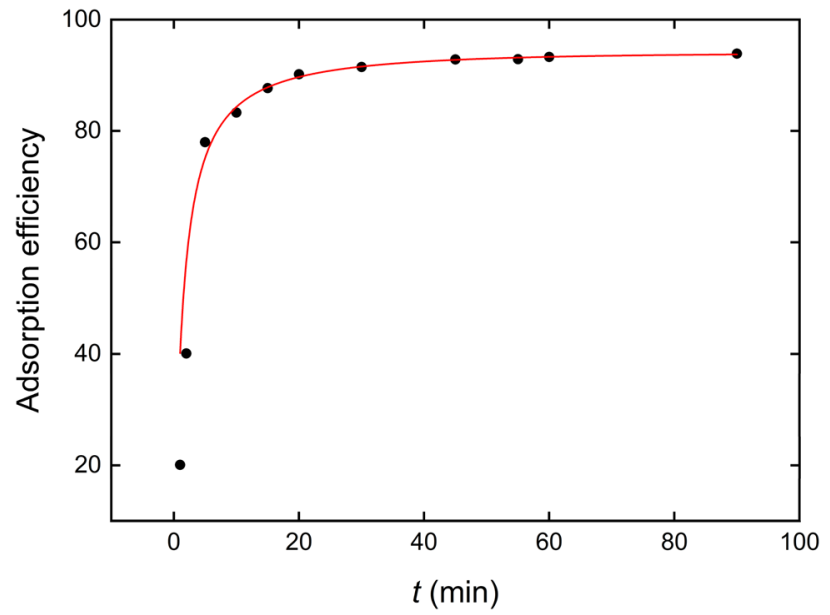

Figure 5. Effect of incubation time on the IB adsorption efficiency. Solid line represents the fit of experimental data to Eq. (1a).

$$
\begin{gathered}
A E=A E_{e}[1-\exp (-k t)] \quad(\text { Lagergren Pseudo }- \text { first order }) \\
\left.\frac{t}{A E}=\frac{1}{V_{0}}+\frac{1}{A E_{e}} t \quad \text { (Pseudo }- \text { second order }\right)
\end{gathered}
$$

In these equations, $A E_{e}$ is the adsorption efficiency in equilibrium, $k$ is the pseudo-first order adsorption rate coefficient, and $V_{0}$ is related with the initial adsorption rate. Nonlinear fits of experimental data for models described by Eqs. (1b) and (1c) gave rise to $R^{2}$ values equal to 0.99933 and 0.99975 , while $\chi^{2}$ values were 1.83 and 0.69 , respectively. To test the validity of the models, F-test (significance $\alpha=0.05)^{49}$, Akaike's information criterion (AIK) and Bayesian information criterion (BIC) ${ }^{50}$ were performed in software Origin 2019. The application of all the tests to Eqs. (1a)-(1c) clearly concludes that the hybrid model, Eq. (1a), is more likely to represent the correct kinetic behavior.

At pH 7 (optimum value to reach the maximum adsorption efficiency) the IB is mostly in its ionized form. However, at this $\mathrm{pH}$, the surface of the nanoparticle will have mainly neutral character, so the procedure does not occur instantaneously, requiring $45 \mathrm{~min}$ to achieve maximum adsorption.

Adsorption isotherms. The adsorption isotherm for the process was determined for several values of the equilibrium adsorption capacity $q_{e}\left(\mathrm{mg} \mathrm{g}^{-1}\right)$ and the equilibrium concentration of adsorbate $C_{e}\left(\mathrm{mg} \mathrm{L}^{-1}\right)$. A Langmuir isotherm model was employed, described by the following equation ${ }^{51}$ : 


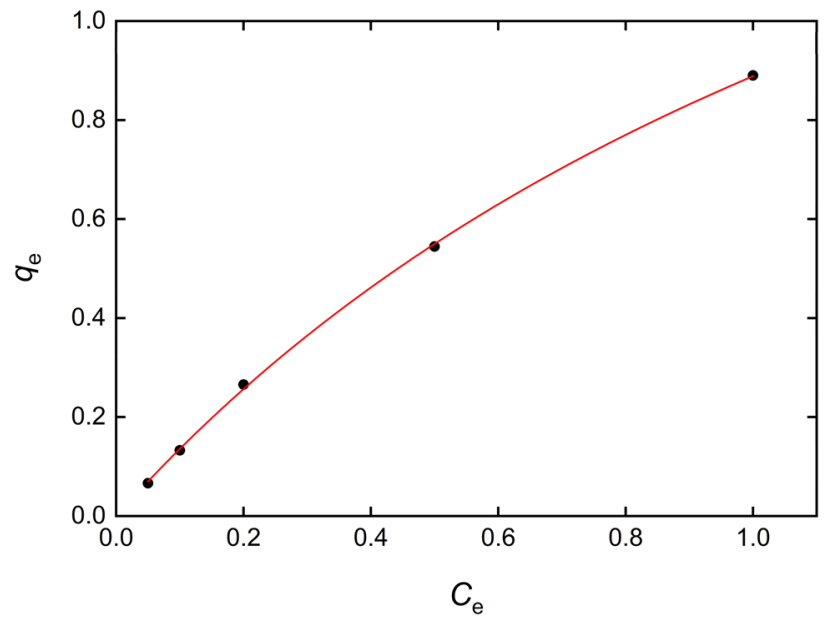

Figure 6. Langmuir isotherm plot $q_{e}$ vs. $C_{e}$ for IB adsorption to $7 \mathrm{mg} \mathrm{Fe}_{3} \mathrm{O}_{4} @ A g N P s$ at $T=298 \mathrm{~K}$ and $\mathrm{pH}=7$. Solid line represents the nonlinear fit to Eq. (2a).

$$
\frac{1}{q_{e}}=\frac{1}{q_{m}}+\frac{1}{K_{L} q_{m} C_{e}}
$$

where $q_{m}$ is the maximum adsorption capacity of adsorbent $\left(\mathrm{mg} \mathrm{g}^{-1}\right)$ and $K_{L}$ is the Langmuir adsorption constant $\left(\mathrm{L} \mathrm{mg}^{-1}\right)$. Figure 6 shows the dependence of $1 / q_{e}$ vs. $1 / C_{e}$ when $7 \mathrm{mg}$ of $\mathrm{Fe}_{3} \mathrm{O}_{4} @ \mathrm{AgNPs}(500 \mu \mathrm{L}$ of suspension) are employed as adsorbent at $\mathrm{pH}=7$ and $T=298 \mathrm{~K}$. The red solid line is the nonlinear fit to the Langmuir equation, $r^{2}=0.99961$ and $\chi^{2}=4.49 \times 10^{-5}$, proving that it is a suitable model for describing the equilibrium behavior of the adsorption experiment.

However, in order to deepen into the isotherm characterization, Freundlich and Temkin isotherms were also fitted to the experimental data:

$$
\begin{gathered}
\log \left(q_{e}\right)=\log \left(K_{F}\right)+\frac{1}{n} \log \left(C_{e}\right) \text { (Freundlich) } \\
q_{e}=\frac{R T}{b} \ln \left(K_{t} C_{e}\right) \text { (Temkin) }
\end{gathered}
$$

In these isotherm models, $K_{F}$ is Freundlich constant, $1 / n$ is the adsorption intensity, $R$ is the gas constant, $T$ is the temperature and $K_{t}$ is Temkin isotherm constant. Nonlinear fits of data for models described by Eqs. (2b) and (2c) gave rise to $R^{2}$ values equal to 0.99622 and 0.92317 , while $\chi^{2}$ were $4.34 \times 10^{-4}$ and 0.00998 , respectively. For the comparison tests computed in Origin 2019, AIC and BIC clearly state that Eq. (2a), Langmuir, is more likely to characterize the equilibrium behavior for the adsorption process. F-test shows that it has not enough information to draw a conclusion. All the results may indicate that Langmuir isotherm characterizes the equilibrium for the adsorption experiment.

Thermodynamic analysis. As mentioned in Sect. 2.3, $\mathrm{Fe}_{3} \mathrm{O}_{4} @ \mathrm{AgNPs}$ is dissolved when the temperature is above $303 \mathrm{~K}$. For temperatures equal to 298 and 303, the adsorption efficiency found gives rise to the same result, $93 \%$. However, to complete the study, we performed a thermodynamic analysis of the adsorption process once the $\mathrm{Fe}_{3} \mathrm{O}_{4} @ \mathrm{AgNPs}$ is dissolved. We studied temperatures $T=313,323,343,353$ and $363 \mathrm{~K}$, for IB concentration $C_{e}=0.002 \mathrm{mg} \mathrm{L}^{-1}$ and $\mathrm{Fe}_{3} \mathrm{O}_{4} @$ AgNPs mass equal to $0.007 \mathrm{~g}$. Van't Hoff equation enables us to determine the standard enthalpy, $\Delta H^{0}\left(\mathrm{~J} \mathrm{~mol}^{-1}\right)$, and standard entropy, $\Delta S^{0}\left(\mathrm{~J} \mathrm{~mol}^{-1} \mathrm{~K}^{-1}\right)$ corresponding to the adsorption process $^{51}$ :

$$
\ln \left(K_{D}\right)=\frac{\Delta S^{0}}{R}-\frac{\Delta H^{0}}{R T}
$$

where $R$ is the gas constant $\left(8.314 \mathrm{~J} \mathrm{~mol}^{-1} \mathrm{~K}^{-1}\right)$ and $T$ is the absolute temperature. Variable $K_{D}$ is the so-called distribution coefficient, defined as:

$$
K_{D}=\frac{q_{e}}{C_{e}}
$$

The standard Gibbs free energy $\Delta G^{0}\left(\mathrm{~kJ} \mathrm{~mol}^{-1}\right)$ is another thermodynamic variable of interest, since can give information about the nature of the adsorption process. Values of $\Delta G^{0}$ within the interval $[-20,0] \mathrm{kJ} \mathrm{mol}^{-1}$ reveal a physisorption process, while $[-20,0] \mathrm{kJ} \mathrm{mol}^{-1}$ are considered as characteristic for chemisorption ${ }^{51} . \Delta G^{0}$ can be determined from as follows: 


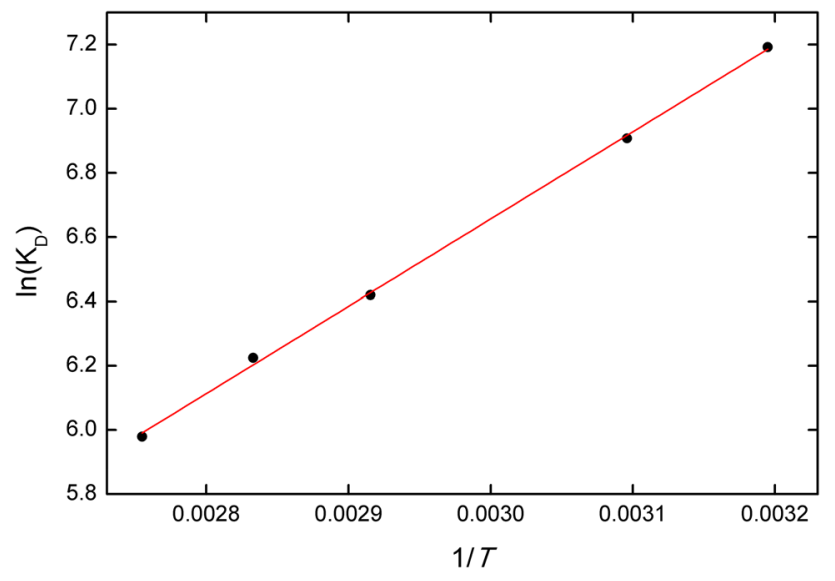

Figure 7. Van't Hoff plot showing the dependence of $\ln \left(K_{D}\right)$ on $1 / T$ for IB adsorption to $7 \mathrm{mg}$ of $\mathrm{Fe}_{3} \mathrm{O}_{4} @ \mathrm{AgNPs}$ at $T=293 \mathrm{~K}, C_{e}=0.002 \mathrm{mg} \mathrm{L}^{-1}$ and $\mathrm{pH}=7$. Solid line represents the linear fit to the experimental data.

\begin{tabular}{|c|c|c|c|}
\hline Water sample & Ibuprofen concentration $\left(\mu \mathrm{g} \mathrm{L}^{-1}\right)^{\mathrm{b}}$ & Adsorption efficiency \% & Adsorption efficiency after doping \% \\
\hline Wastewater $^{\mathrm{a}}$ & $2.31 \pm 0.05$ & 93.1 & 92.9 \\
\hline River water & $0.62 \pm 0.02$ & 92.8 & 93.0 \\
\hline Drinking water & Not detected & - & 93.1 \\
\hline Seawater & Not detected & - & 92.8 \\
\hline
\end{tabular}

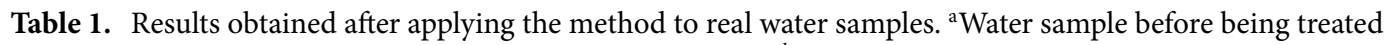
at the wastewater treatment plant in the city of Murcia, Spain. ${ }^{b}$ Each sample was analyzed by triplicate.

$$
\Delta G^{0}=-R T \ln \left(K_{D}\right)
$$

Figure 7 shows the dependence of $\ln \left(K_{D}\right)$ on $1 / T$ for temperatures $T=313,323,343,353$ and $363 \mathrm{~K}$. The red solid line represents the linear fit to the experimental data $r^{2}=0.9989$. From Eq. (4) we determine, $\Delta H^{0}=-22.57\left(\mathrm{~kJ} \mathrm{~mol}^{-1}\right)$ and $\Delta S^{0}=12.4\left(\mathrm{~J} \mathrm{~mol}^{-1} \mathrm{~K}^{-1}\right)$, which reveals and exotermic process with an increase of randomness at solid/liquid interface for the adsorption procedure ${ }^{51}$. From Eq. (5) we determine that $\Delta G^{0}$ values lie within the range $[-18.71,-18.03] \mathrm{kJ} \mathrm{mol}^{-1}$, indicative of a physisorption process.

Ibuprofen adsorption in real water samples. The proposed method for the adsorption of ibuprofen in waters was applied to real water samples partially contaminated with this chemical compound. It was found that the concentration of the pollutant in these samples was low or not detected, so they were doped with a known concentration of ibuprofen $\left(0.2 \mathrm{mg} \mathrm{L}^{-1}\right)$ in order to check the viability of the proposed process. Adsorption efficiencies close to $93 \%$ were achieved in all cases, thus enabling the method as suitable for its application in real water samples. The results are summarized in Table 1.

Desorption and recycling studies. In order to carry out the desorption of the IB from the surface of the nanoparticles, $1 \mathrm{ml}$ of a solution of nitric acid at $\mathrm{pH} 1$ was used. For that value, interactions between adsorbent and adsorbate are weakened due to the effect of the ionic strength, as stated in "Effect of pH on IB adsorption", thus favoring the desorption process. When the IB adsorption is carried out, after separation from the aqueous solution with the magnet, this solution is decanted. Then, $1 \mathrm{ml}$ of the nitric acid solution is added and the mixture is sonicated for $3 \mathrm{~min}$. After that, the adsorbent is removed with the magnet and the acid solution is quantified by high performance liquid chromatography, demonstrating that the IB total has been desorbed. Recycling studies were carried out showing that $\mathrm{Fe}_{3} \mathrm{O}_{4} @ \mathrm{AgNPs}$ can be used during two additional successive adsorption cycles without losing adsorption capacity. In the fourth adsorption cycle, the capacity decreases down to $89.4 \%$. The results are shown in Table 2.

\section{Conclusion}

This work proposes a novel simple method for the adsorption of IB in water using $\mathrm{Fe}_{3} \mathrm{O}_{4} @ \mathrm{AgNPs}$. The results show a maximum IB removal efficiency of $93 \%$ from aqueous solutions, achieving the maximum adsorption at neutral $\mathrm{pH}$ and room temperature. The procedure takes $45 \mathrm{~min}$ and employs a dose of adsorbent equal to $7 \mathrm{mg}$ in $500 \mu \mathrm{L}$ of suspension, which can be completely removed from the medium using a magnet. The characterization of the adsorbent by means of microscopy, spectroscopy and calorimetry techniques reveal the presence of $\mathrm{Ag}$ in $\mathrm{Fe}_{3} \mathrm{O}_{4} @ \mathrm{AgNPs}$ and the adsorption of IB. The adsorption equilibrium is characterized by a Langmuir 


\begin{tabular}{|l|l|}
\hline Adsorption cycle & Adsorption capacity (\%) \\
\hline 1 & 93 \\
\hline 2 & 93 \\
\hline 3 & 93 \\
\hline 4 & 89.4 \\
\hline
\end{tabular}

Table 2. Recycling studies. Data for the four recycling cycles are shown.

isotherm. As a final remark, a simple method in acid media by using nitric acid $\mathrm{pH}=1$ has been proposed for the recycling and reuse of the adsorbent, which reaches $89.3 \%$ removal efficiency after three regenerations. The method presented in this work is suitable for removal of IB-like emergent pollutants from waters which cross the barriers of purification systems due to their low concentrations.

Received: 14 April 2020; Accepted: 5 October 2020

Published online: 26 October 2020

\section{References}

1. Bernal, V., Giraldo, L. \& Moreno-Piraján, J. C. Comparative calorimetry study of the phenol and acetaminophen adsorption on activated carbon in aqueous solution. Revista Colombiana de Ciencias Químico - Farmacéuticas 44, 90-106. https://doi.org/10.15446 /rcciquifa.v44n1.54284 (2015).

2. Iqbal, M. N. Antibiotics traces in the aquatic environment: persistence and adverse environmental impact. Curr. Opin. Environ. Sci. Health 13, 68-74. https://doi.org/10.1016/j.coesh.2019.11.005 (2020).

3. Barcelo, D. Emerging pollutants in water analysis. Trac-Trends Anal. Chem. 22, XIV-XVI. https://doi.org/10.1016/s0165 -9936(03)01106-3 (2003).

4. Maia Bila, D. \& Dezotti, M. Endocrine disrupters in the environment: Part 1: effects and consequences. Quim. Nova 30,651-666. https://doi.org/10.1590/s0100-40422007000300027 (2007).

5. Fent, K., Weston, A. A. \& Caminada, D. Ecotoxicology of human pharmaceuticals (vol 76, pg 122, 2006). Aquat. Toxicol. 78, 207-207. https://doi.org/10.1016/j.aquatox.2006.02.006 (2006).

6. Papamija, M. S. \& Víctor, A. Degradación fotocatalítica del ibuprofeno empleando dióxido de titanio. Revista de Ingeniería 31, 57-53 (2010).

7. Zuccato, E. et al. Pharmaceuticals in the environment in Italy: Causes, occurrence, effects and control. Environ. Sci. Pollut. Res. 13, 15-21. https://doi.org/10.1065/espr2006.01.004 (2006).

8. Teijon, G., Candela, L., Tamoh, K., Molina-Diaz, A. \& Fernandez-Alba, A. R. Occurrence of emerging contaminants, priority substances (2008/105/CE) and heavy metals in treated wastewater and groundwater at Depurbaix facility (Barcelona, Spain). Sci. Total Environ. 408, 3584-3595. https://doi.org/10.1016/j.scitotenv.2010.04.041 (2010).

9. Navrozidou, E., Melidis, P. \& Ntougias, S. Biodegradation aspects of ibuprofen and identification of ibuprofen-degrading microbiota in an immobilized cell bioreactor. Environ. Sci. Pollut. Res. Int. 26, 14238-14249. https://doi.org/10.1007/s11356-019-04771 -5 (2019).

10. Greenstein, K. E., Lew, J., Dickenson, E. R. V. \& Wert, E. C. Investigation of biotransformation, sorption, and desorption of multiple chemical contaminants in pilot-scale drinking water biofilters. Chemosphere 200, 248-256. https://doi.org/10.1016/j.chemospher e.2018.02.107 (2018).

11. Shafeei, N., Asadollahfardi, G., Moussavi, G. \& Boojar, M. M. A. Degradation of ibuprofen in the photocatalytic process with doped $\mathrm{TiO} 2$ as catalyst and UVA-LED as existing source. Desalin. Water Treatm. 142, 341-352. https://doi.org/10.5004/dwt.2019.23214 (2019).

12. Jin, X. et al. Role of Al-based coagulants on a hybrid ozonation-coagulation (HOC) process for WWTP effluent organic matter and ibuprofen removal. Environ. Sci. Water Res. Technol. 5, 599-608. https://doi.org/10.1039/c8ew00756j (2019).

13. Amor, C. et al. Winery wastewater treatment by sulphate radical based-advanced oxidation processes (SR-AOP): Thermally vs UV-assisted persulphate activation. Process Saf. Environ. Prot. 122, 94-101. https://doi.org/10.1016/j.psep.2018.11.016 (2019).

14. Zhu, Y. et al. CaCu3Ti4O12, an efficient catalyst for ibuprofen removal by activation of peroxymonosulfate under visible-light irradiation. Environ. Chem. Lett. 17, 481-486. https://doi.org/10.1007/s10311-018-0776-x (2019).

15. Jothinathan, L. \& Hu, J. Kinetic evaluation of graphene oxide based heterogenous catalytic ozonation for the removal of ibuprofen. Water Res. 134, 63-73. https://doi.org/10.1016/j.watres.2018.01.033 (2018).

16. Rafati, L., Ehrampoush, M. H., Rafati, A. A., Mokhtari, M. \& Mahvi, A. H. Removal of ibuprofen from aqueous solution by functionalized strong nano-clay composite adsorbent: kinetic and equilibrium isotherm studies. Int. J. Environ. Sci. Technol. 15, 513-524. https://doi.org/10.1007/s13762-017-1393-0 (2018).

17. Ahmadzadeh, S. \& Dolatabadi, M. Removal of acetaminophen from hospital wastewater using electro-Fenton process. Environ. Earth Sci. 77, 1. https://doi.org/10.1007/s12665-017-7203-7 (2018).

18. Leone, V., Chanese, S., Musmarra, D., Erto, A. \& Iovino, P. Ibuprofen adsorption on organo-zeolite: experimental and modelling analysis. Adv. Sci. Lett. 23, 5876-5878. https://doi.org/10.1166/asl.2017.9055 (2017).

19. Guedidi, H., Reinert, L., Soneda, Y., Bellakhal, N. \& Duclaux, L. Adsorption of ibuprofen from aqueous solution on chemically surface-modified activated carbon cloths. Arab. J. Chem. 10, S3584-S3594. https://doi.org/10.1016/j.arabjc.2014.03.007 (2017).

20. Makila, E. et al. Influence of surface chemistry on ibuprofen adsorption and confinement in mesoporous silicon microparticles. Langmuir 32, 13020-13029. https://doi.org/10.1021/acs.langmuir.6b03413 (2016).

21. Egashira, M., Yoshimoto, N. \& Morita, M. Capacitance of activated carbon with ibuprofen adsorption. Electrochemistry 86, $190-193$. https://doi.org/10.5796/electrochemistry.17-00099 (2018).

22. Frohlich, A. C., Ocampo-Perez, R., Diaz-Blancas, V., Salau, N. P. G. \& Dotto, G. L. Three-dimensional mass transfer modeling of ibuprofen adsorption on activated carbon prepared by sonication. Chem. Eng. J. 341, 65-74. https://doi.org/10.1016/j.cej.2018.02.020 (2018).

23. Sivarajasekar, N. et al. Statistical optimization studies on adsorption of ibuprofen onto Albizialebbeck seed pods activated carbon prepared using microwave irradiation. Mater. Today Proc. 5, 7264-7274 (2018).

24. Martin, J. et al. Evaluation of a modified mica and montmorillonite for the adsorption of ibuprofen from aqueous media. Appl. Clay Sci. 171, 29-37. https://doi.org/10.1016/j.clay.2019.02.002 (2019). 
25. Coimbra, R. N., Escapa, C. \& Otero, M. Adsorption separation of analgesic pharmaceuticals from ultrapure and waste water: batch studies using a polymeric resin and an activated carbon. Polymers 10, 1. https://doi.org/10.3390/polym10090958 (2018).

26. Bello, O. S., Alao, O. C., Alagbada, T. C. \& Olatunde, A. M. Biosorption of ibuprofen using functionalized bean husks. Sustain. Chem. Pharm. 13, 1. https://doi.org/10.1016/j.scp.2019.100151 (2019).

27. Coimbra, R. N., Calisto, V., Ferreira, C. I. A., Esteves, V. I. \& Otero, M. Removal of pharmaceuticals from municipal wastewater by adsorption onto pyrolyzed pulp mill sludge. Arab. J. Chem. 12, 3611-3620. https://doi.org/10.1016/j.arabjc.2015.12.001 (2019).

28. Santaeufemia, S., Torres, E. \& Abalde, J. Biosorption of ibuprofen from aqueous solution using living and dead biomass of the microalga Phaeodactylum tricornutum. J. Appl. Phycol. 30, 471-482. https://doi.org/10.1007/s10811-017-1273-5 (2018).

29. Liu, S. H. \& Tang, W. T. Photodecomposition of ibuprofen over g-C3N4/Bi2WO6/rGO heterostructured composites under visible/ solar light. Sci. Total Environ. 731, 11. https://doi.org/10.1016/j.scitotenv.2020.139172 (2020).

30. Bayoumy, A. M., Omar, A., El-Sayed, E. M. \& Ibrahim, M. Removal of pharmaceuticals from aquatic environment using modified biomaterials. Biointerface Res. Appl. Chem. 10, 5986-5993. https://doi.org/10.33263/briac104.986993 (2020).

31. Abukhadra, M. R., Refay, N. M., Nadeem, A., El-Sherbeeny, A. M. \& Ibrahim, K. E. Insight into the role of integrated carbohydrate polymers (starch, chitosan, and beta-cyclodextrin) with mesoporous silica as carriers for ibuprofen drug; equilibrium and pharmacokinetic properties. Int. J. Biol. Macromol. 156, 537-547. https://doi.org/10.1016/j.ijbiomac.2020.04.052 (2020).

32. Wang, W. J. et al. Rapid and efficient removal of organic micropollutants from environmental water using a magnetic nanoparticlesattached fluorographene-based sorbent. Chem. Eng. J. 343, 61-68. https://doi.org/10.1016/j.cej.2018.02.101 (2018).

33. Shi, E. et al. Ag2S-doped core-shell nanostructures of Fe3O4@Ag3PO4 ultrathin film: major role of hole in rapid degradation of pollutants under visible light irradiation. Chem. Eng. J. 366, 123-132. https://doi.org/10.1016/j.cej.2019.02.018 (2019).

34. Mohammadi-Aghdam, S., Valinezhad-Saghezi, B., Mortazavi, Y. \& Qhoreishi, S. M. Modified Fe3O4/HAp magnetically nanoparticles as the Carrier for Ibuprofen: adsorption and release study. Drug Res. 69, 93-99. https://doi.org/10.1055/a-0647-1765 (2019).

35. Yin, R., Sun, J., Xiang, Y. \& Shang, C. Recycling and reuse of rusted iron particles containing core-shell Fe-FeOOH for ibuprofen removal: adsorption and persulfate-based advanced oxidation. J. Clean. Prod. 178, 441-448. https://doi.org/10.1016/j.jclep ro.2018.01.005 (2018).

36. Ali, N. et al. Environmental perspectives of interfacially active and magnetically recoverable composite materials: a review. Sci. Total Environ. 670, 523-538. https://doi.org/10.1016/j.scitotenv.2019.03.209 (2019).

37. Iovino, P., Canzano, S., Capasso, S., Erto, A. \& Musmarra, D. A modeling analysis for the assessment of ibuprofen adsorption mechanism onto activated carbons. Chem. Eng. J. 277, 360-367. https://doi.org/10.1016/j.cej.2015.04.097 (2015).

38. Kamarudin, N. H. N. et al. Elucidation of acid strength effect on ibuprofen adsorption and release by aluminated mesoporous silica nanoparticles. Rsc Adv. 5, 30023-30031. https://doi.org/10.1039/c4ra16761a (2015).

39. Vicente-Martinez, Y., Caravaca, M. \& Soto-Meca, A. Total removal of $\mathrm{Hg}$ (II) from wastewater using magnetic nanoparticles coated with nanometric Ag and functionalized with sodium 2-mercaptoethane sulfonate. Environ. Chem. Lett. 1, 1. https://doi. org/10.1007/s10311-020-00987-x (2020).

40. Rachel, N. Y. in Materials Sciences and Applications (2017).

41. Oh, S., Shin, W. S. \& Kim, H. T. Effects of pH, dissolved organic matter, and salinity on ibuprofen sorption on sediment. Environ. Sci. Pollut. Res. 23, 22882-22889. https://doi.org/10.1007/s11356-016-7503-6 (2016)

42. Guedidi, H. et al. The effects of the surface oxidation of activated carbon, the solution $\mathrm{pH}$ and the temperature on adsorption of ibuprofen. Carbon 54, 432-443. https://doi.org/10.1016/j.carbon.2012.11.059 (2013).

43. Baccar, R., Sarra, M., Bouzid, J., Feki, M. \& Blanquez, P. Removal of pharmaceutical compounds by activated carbon prepared from agricultural by-product. Chem. Eng. J. 211, 310-317. https://doi.org/10.1016/j.cej.2012.09.099 (2012).

44. Moreno-Castilla, C. Adsorption of organic molecules from aqueous solutions on carbon materials. Carbon 42, 83-94. https://doi. org/10.1016/j.carbon.2003.09.022 (2004)

45. Behera, S. K., Oh, S. Y. \& Park, H. S. Sorptive removal of ibuprofen from water using selected soil minerals and activated carbon. Int. J. Environ. Sci. Technol. 9, 85-94. https://doi.org/10.1007/s13762-011-0020-8 (2012).

46. Tan, P. et al. Adsorption of $\mathrm{Cu} 2+, \mathrm{Cd} 2+$ and $\mathrm{Ni} 2+$ from aqueous single metal solutions on graphene oxide membranes. J. Hazard. Mater. 297, 251-260. https://doi.org/10.1016/j.jhazmat.2015.04.068 (2015).

47. Islam, M. A., Khan, M. R. \& Mozumder, S. I. Adsorption equilibrium and adsorption kinetics: a unified approach. Chem. Eng. Technol. 27, 1095-1098. https://doi.org/10.1002/ceat.200402084 (2004).

48. Sen Gupta, S. \& Bhattacharyya, K. G. Kinetics of adsorption of metal ions on inorganic materials: a review. Adv. Colloid Interface Sci. 162, 39-58. https://doi.org/10.1016/j.cis.2010.12.004 (2011).

49. Baggiani, C., Giraudi, G., Giovannoli, C., Tozzi, C. \& Anfossi, L. Adsorption isotherms of a molecular imprinted polymer prepared in the presence of a polymerisable template: indirect evidence of the formation of template clusters in the binding site. Anal. Chim. Acta 504, 43-52. https://doi.org/10.1016/s0003-2670(03)00671-8 (2004).

50. Santos Lins, P. V. et al. Adsorption of a non-steroidal anti-inflammatory drug onto MgAl/LDH-activated carbon composite: experimental investigation and statistical physics modeling. Colloids Surf. A Physicochem. Eng. Aspects 586, 1. https://doi.org/10.1016/j. colsurfa.2019.124217 (2020).

51. Vicente-Martínez, Y., Soto-Meca, A., De Francisco-Ortiz, O. \& Gimeno, F. Graphene oxide and graphene oxide functionalized with silver nanoparticles as adsorbents of phosphates in waters: a comparative study. Sci. Total Environ. 709, 1. https://doi.org/10.1016/j. scitotenv.2019.136111 (2020).

\section{Acknowledgements}

The authors want to thank the University Centre of Defence at the Spanish Air Force Academy, MDE-UPCT, for financial support.

\section{Author contributions}

Y.V.-M. has designed, directed and carried out the experimental work in the laboratory. R.S.-G. has carried out the experimental laboratory work. M.C. and A.S.-M. designed the study, performed the thermodynamic study, analysis of the isotherms and characterization of the adsorbent. Y.V.-M., M.C. and A.S.-M. have written and revised the manuscript.

\section{Competing interests}

The authors declare no competing interests.

\section{Additional information}

Supplementary information is available for this paper at https://doi.org/10.1038/s41598-020-75223-1.

Correspondence and requests for materials should be addressed to Y.V.-M. 
Reprints and permissions information is available at www.nature.com/reprints.

Publisher's note Springer Nature remains neutral with regard to jurisdictional claims in published maps and institutional affiliations.

(c) (i) Open Access This article is licensed under a Creative Commons Attribution 4.0 International License, which permits use, sharing, adaptation, distribution and reproduction in any medium or format, as long as you give appropriate credit to the original author(s) and the source, provide a link to the Creative Commons licence, and indicate if changes were made. The images or other third party material in this article are included in the article's Creative Commons licence, unless indicated otherwise in a credit line to the material. If material is not included in the article's Creative Commons licence and your intended use is not permitted by statutory regulation or exceeds the permitted use, you will need to obtain permission directly from the copyright holder. To view a copy of this licence, visit http://creativecommons.org/licenses/by/4.0/.

(C) The Author(s) 2020 